\title{
Suitability Analysis for DGPS Radio Beacon Establishment at Port Klang Malaysia
}

\author{
Muhammad Farid Mohd Yazair, Tajul Ariffin Musa, Rusli Othman, \\ Ahmad Zuri Sha'ameri, Wan Anom Wan Aris, Ivin Amri Musliman, Muhammad Syazwan Ab \\ Razak, Roslee Mat Yusof, Alimuddin Amirudin
}

\begin{abstract}
Differential Global Positioning System (DGPS) is a positioning technique which provide safety in navigation to support maritime activities. Marine Department of Malaysia has established Sistem Pelayaran Satelit (SISPELSAT) as safety to aid maritime navigation activities system over the coast of Peninsular Malaysia. The aim of this study is to investigate the location suitability for a new SISPELSAT radio beacon station at Port Klang, Selangor. The work involves three (3) parts; (1) multipath analysis, (2) GPS and Medium Frequency (MF) signal interference investigation, and (3) DGPS correction transmission signal simulation coverage. It has found that, the location has an acceptable multipath value of MP1 and MP2 at $0.4097 \mathrm{~m}$ and $0.3654 \mathrm{~m}$ respectively. Meanwhile, no signal interferences on GPS and MF radio signals have found at the proposed location. In addition, the signal simulation shows that the location of Port Klang station are able to provide optimum DGPS coverage for the area of Melaka Straits.
\end{abstract}

Index Term: Radio beacon; SISPELSAT; DGPS.

\section{INTRODUCTION}

Precise navigation is one of the key factor for providing safety of vessel navigation [1]. Generally, precise navigation as offered by single-based Differential Global Positioning System (DGPS) solution can support the navigation safety with precision approximately 1 to 5 meters, hence it is sufficient in providing navigation safety [2]. The Marine Department Malaysia has initiated the development of

Revised Manuscript Received on 14 September, 2019.

Muhammad Farid Mohd Yazai, Geomatic Innovation Research Group (GnG), Faculty of Built Environment and Survey, Universiti Teknologi Malaysia, 81310 Johor Bahru, Johor, Malaysia. faridyazair@gmail.com

Tajul Ariffin Musa, Geomatic Innovation Research Group (GnG), Faculty of Built Environment and Survey, Universiti Teknologi Malaysia, 81310 Johor Bahru, Johor, Malaysia

Rusli Othman, Geomatic Innovation Research Group (GnG), Faculty of Built Environment and Survey, Universiti Teknologi Malaysia, 81310 Johor Bahru, Johor, Malaysia

Ahmad Zuri Sha'ameri, Geomatic Innovation Research Group (GnG), Faculty of Built Environment and Survey, Universiti Teknologi Malaysia, 81310 Johor Bahru, Johor, Malaysia

Wan Anom Wan Aris, Geomatic Innovation Research Group (GnG), Faculty of Built Environment and Survey, Universiti Teknologi Malaysia, 81310 Johor Bahru, Johor, Malaysia

Ivin Amri Musliman, Geomatic Innovation Research Group (GnG), Faculty of Built Environment and Survey, Universiti Teknologi Malaysia, 81310 Johor Bahru, Johor, Malaysia

Muhammad Syazwan Ab Razak, Geomatic Innovation Research Group (GnG), Faculty of Built Environment and Survey, Universiti Teknologi Malaysia, 81310 Johor Bahru, Johor, Malaysia

Roslee Mat Yusof, Marine Department Malaysia, Ibu Pejabat Laut, Pet Surat 12, Jalan Limbungan, 42007 Pelabuhan Klang, Selangor, Malaysia

Alimuddin Amirudin, Marine Department Malaysia, Ibu Pejabat Laut, Peti Surat 12, Jalan Limbungan, 42007 Pelabuhan Klang, Selangor, Malaysia
DGPS service known as Sistem Pelayaran Satelit (SISPELSAT) in 2003 to satisfy maritime navigation requirements over Malaysian's coastal areas and inland waterways $[3,4,5]$. Currently, the SISPELSAT consist of four (4) Minimum Shift Keying (MSK) radio beacons and two (2) monitoring stations in Peninsular Malaysia [4,6]. Each SISPELSAT stations are equipped with Global Positioning System (GPS) antennas, GPS receivers and MSK radio-based communication. The SISPELSAT stations are utilized in transmitting real-time DGPS correction in Medium Frequency (MF) that ranging from 283.5 to 325 $\mathrm{kHz}$. Figure 1 shows the locations of SISPELSAT stations in Peninsular Malaysia with their assigned radio frequencies.

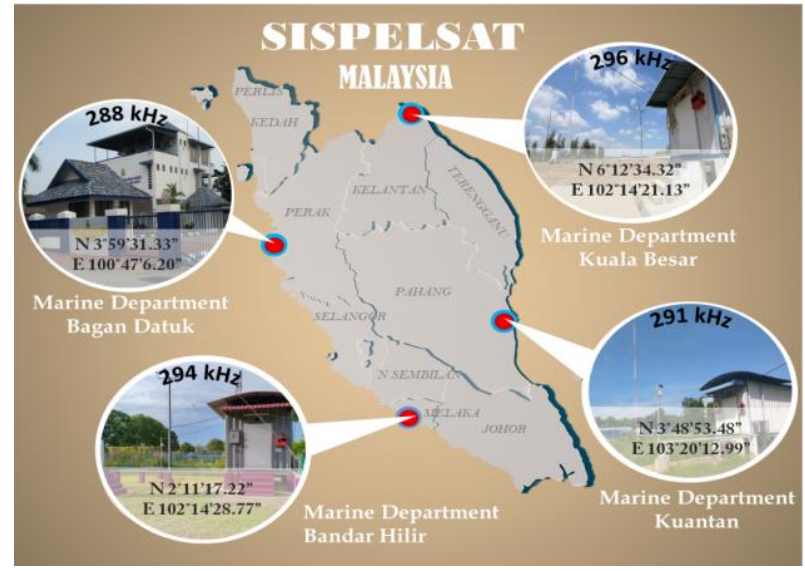

Fig. Location of SISPELSAT Radio Beacon Stations in Peninsular Malaysia.

According to Figure 1, there is no SISPELSAT station located at Port Klang which is known as the busiest port in Malaysia. It is a doubt as well, that the existing SISPELSAT stations of Bagan Datuk and Melaka could transmit the DGPS signal correction at Port Klang due to long distance separation between these locations. For this reason, a DGPS signal simulation coverage from Bagan Datuk and Melaka stations to Port Klang have been generated in Figure 2. From this simulation results, Port Klang only received around 30 $\mathrm{dB}$ and below $10 \mathrm{~dB}$ for maximum and minimum coverage of Signal to Noise Ratio (SNR) value, respectively. International Telecommunication Union stated that, the minimum criteria for coverage set out is more than $7 \mathrm{~dB}$ SNR [7]. It indicates that the value is close to unusable for minimum coverage and fair value for maximum coverage at Port Klang station. This is, however, not a good SNR indicator for busiest port in the world such as Port Klang.

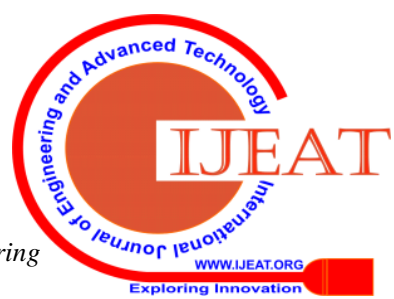




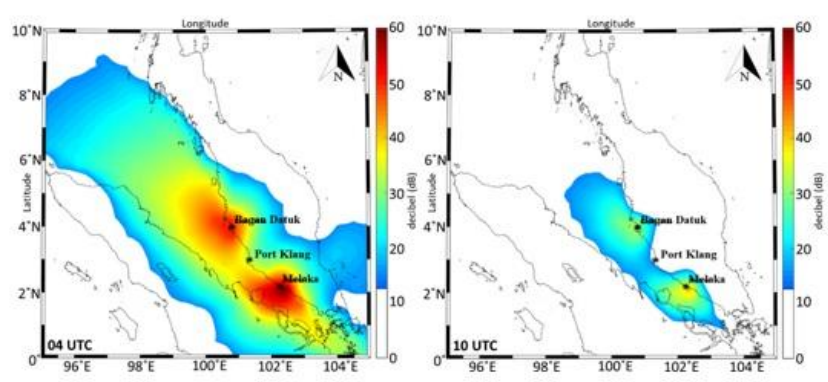

Fig 2. Simulation of maximum and minimum DGPS signal coverage for both Bagan Datuk and Melaka SISPELSAT stations.

Hence, a possible solution that can be considered is by establishing a new radio beacon station to broadcast DGPS signal at Port Klang. This paper will present results from several studies that have been carried out to determine the suitability of establishing a new SISPELSAT radio beacon station at Port Klang.

\section{SISPELSAT - THE SETUP}

SISPELSAT as radio beacon station comprises of two (2) main components which are:(1) GPS reference \& integrity receiver and computer and; (2) MSK radio transmitter and antenna. GPS reference \& integrity receiver is essentially for continuously 24-Hour operational of the system. Aside from necessitating the computer, SISPELSAT has been setup to have two (2) pair of GPS receivers and each pair consist of 2 antennas; first antenna for generating the Pseudo Range Correction (PRC), second antenna for integrity [8]. Ideally, the GPS antenna should be placed at an excellent GPS geometry environment (clear sky view) and having a minimum multipath effect in receiving L1 (1575.42 MHz) and L2 (1227.60 MHz) GPS signals. The multipath effect could reduce the measurement quality when approaching the GPS antennas; it is course by reflection of satellite signal on reflecting surface makes the signal travel indirectly $[9,10]$. The GPS antenna should be established on a stable pillar which is rigidly connected to building structure or anchored directly and securely to the ground for effectively eliminate the antenna motion. Figure 3 shows the infrastructure of Bagan Datuk SISPELSAT station with its GPS antennas and MSK radio transmitter.

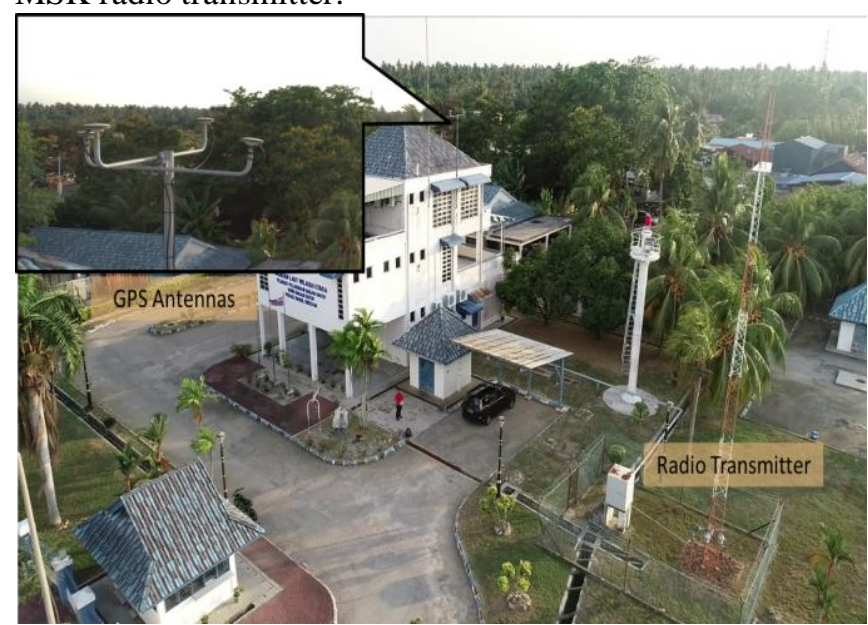

Fig 3. GPS antennas and MSK Radio Transmitter of Bagan Datuk station.
The MSK radio wave basically use Medium Frequency (MF) in transmitting their signal with ground and sky wave propagation. Ground wave signals propagate by following the terrain of the earth and also dependent on nature of the surface for instance ground conductivity and the dielectric constant of the Earth. Consequently, sea water gives good field strength compared to land [11]. Radio waves propagating through a radio channel may undergo reflection, refraction, diffraction, interference and scattering [12]. Moreover, the signal propagation is also affected by the time which relative to sunrise or sunset. Usually, six (6) hours after sunset is the smallest loss of energy while one (1) hour after sunrise is the biggest energy loss. Meanwhile, sky-wave ionospheric propagation is not possible during the day because of the attenuation of the signals on these frequencies caused by the D-region in the ionosphere. In view of this, radio communications stations such as SISPELSAT need to rely on the ground-wave propagation to achieve their coverage.

\section{METHODOLOGY}

The overall methodology for suitability analysis of establishing a new SISPELSAT radio beacon station at Port Klang is illustrated as in Figure 4:

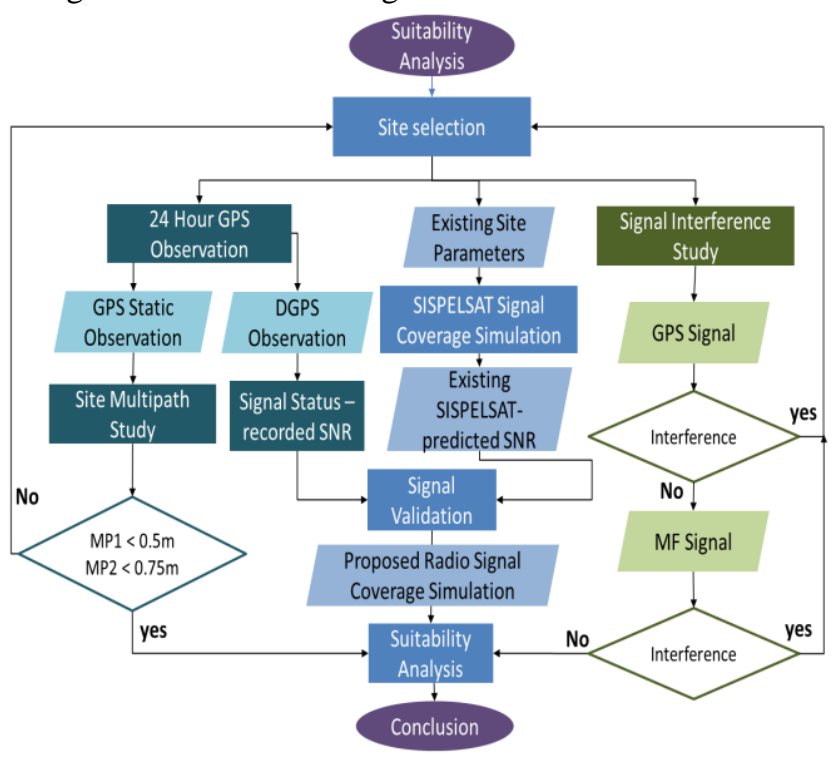

Fig 4. Methodology Flowchart.

The proposed location for this study is at Maritime Transport Training Institute (MATRAIN), Port Klang at Latitude $2^{\circ} 59^{\prime} 15.4$ " and Longitude $101^{\circ} 23^{\prime} 16.7^{\prime}$ ' by considering it is near the Port Klang harbour and open area for radio antenna transmitter establishment as shown in Figure 5. 

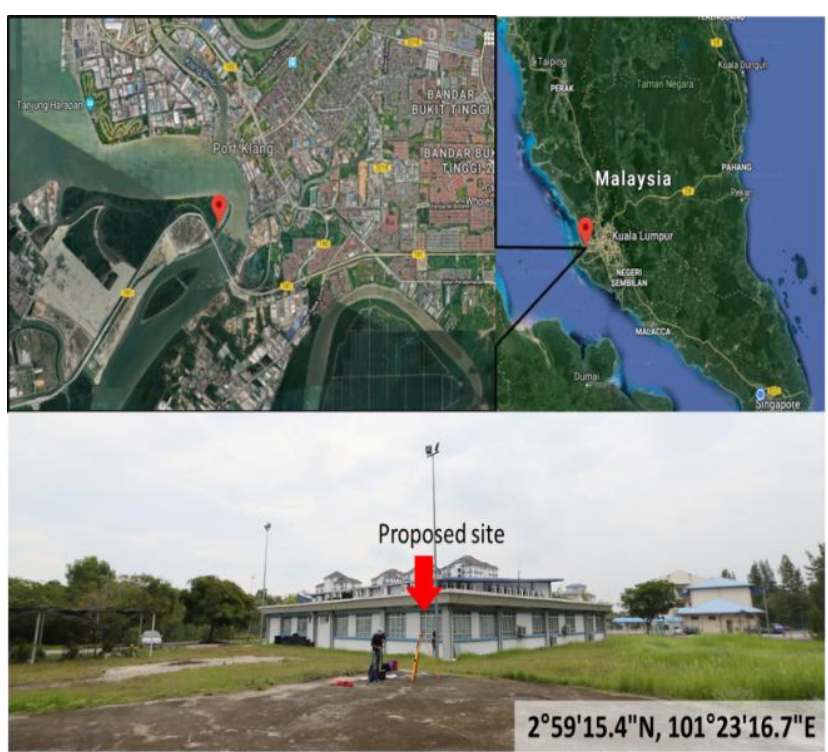

Fig 5. Proposed location of SISPELSAT radio beacon station at MATRAIN Port Klang.

Subsequently, the proposed site has undergone three (3) main type of assessments; 1) 24 Hour GPS \& DGPS observation for multipath analysis and SNR validation; 2) DGPS signal coverage simulation; and, 3) Signal interference investigation. The detail of the assessment is described below.

\section{A. GPS Observation}

During the inspection, the proposed location of the radio beacon station has been setup with a GPS antenna temporarily for site multipath checking and SNR validation. A continuous GPS and DGPS observation have been conducted from $11^{\text {th }}$ July 2018 (begin at $09.23 \mathrm{am}$ ) until $12^{\text {th }}$ July 2018(end at 09.57am), i.e., more than 24 hours with $1 \mathrm{~Hz}$ data sampling rate at 0 elevation mask. Figure 6 below represents the GPS and DGPS observation technique involved in multipath and SNR validation study.

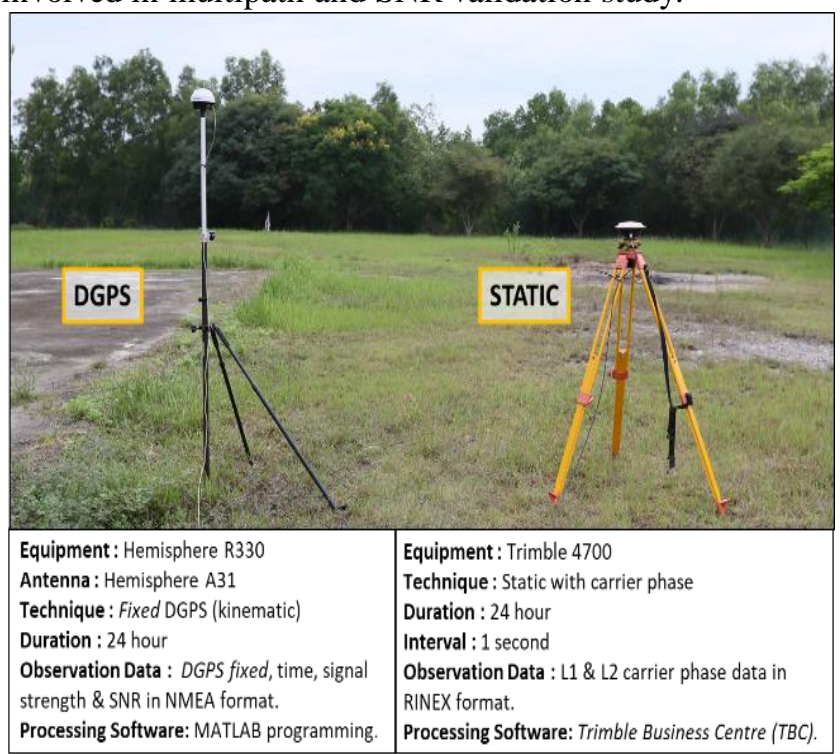

Fig 6. GPS observation at the proposed radio beacon location of MATRAIN Port Klang.

The data processing for this site multipath study has been divided into 4 sessions with each session represents six (6) hours of observation time windows. The results have been analysed for both signal multipath 1 (MP1) for L1 carrier phase and multipath 2 (MP2) for L2 carrier phase. Hence, highest time window multipath value has been identified. Moreover, DGPS observation has been carried out by receiving the DGPS correction from Melaka SISPELSAT station with distance separation about $140 \mathrm{~km}$ and the SNR values as received at Port Klang have been recorded. This DGPS observation data is compared with DGPS signal coverage simulation from Melaka SISPELSAT station as predicted value.

\section{B. DGPS Signal Coverage Simulation}

For MF radio signal coverage simulation, some parameters are being considered by following the established SISPELSAT radio transmitter stations as shown in Table 1.

Table 1: MF radio signal coverage simulation criteria.

\begin{tabular}{|c|c|c|}
\hline No & PARAMETER & CRITERIA \\
\hline \multirow{2}{*}{1} & \multirow{2}{*}{ TIME (UTC) } & MAX coverage (4 UTC) \\
\hline & & MIN coverage (10 UTC) \\
\hline 2 & Frequency & $300 \mathrm{KHz}$ \\
\hline 3 & Power & 1.0 Kilowatt \\
\hline 4 & Pred.Conf & $90 \%$ \\
\hline 5 & Positions & Latitude \& Longitude \\
\hline 6 & Dry Ground Sea State & $2(10 \mathrm{Knott})$ \\
\hline 7 & ATM. NOISE & CCIR 322 \\
\hline 8 & Manmade Noise & -130 dBW/Hz@3MHz \\
\hline 10 & Required SNR & 12 \\
\hline 11 & T-index & -2 \\
\hline 12 & $\begin{array}{l}\text { Transmitter: Vertical } \\
\text { monopole }\end{array}$ & L:30m, H:5m, Eff: $100 \%$ \\
\hline 13 & $\begin{array}{l}\text { Receiver: Vertical } \\
\text { monopole }\end{array}$ & L:1m, H:2m, Eff: $100 \%$ \\
\hline 14 & Rx Bandwidth & $3 \mathrm{kHz}$ \\
\hline
\end{tabular}

These parameters have been used in estimating the signal propagation simulation by using Ground Wave Prediction System (GWPS) software. The signal coverage simulation is generated for maximum and minimum coverage in ASCII format. Consequently, the ASCII data have been plotted in map form for visualisation and analysis.

\section{Signal Interference Investigation}

This assessment is meant to identify any signal interference to the GPS and MF radio frequency at the proposed radio beacon location. The study has utilised spectrum analyser equipment in order to scan the existing radio signal that might affect the GPS and MF signal. Figure 7 shows the signal interference study is held at Port Klang. The signal range scanned for the GPS is from 1.1 to $1.8 \mathrm{GHz}$ while 250 to $350 \mathrm{kHz}$ for the MF signals. 


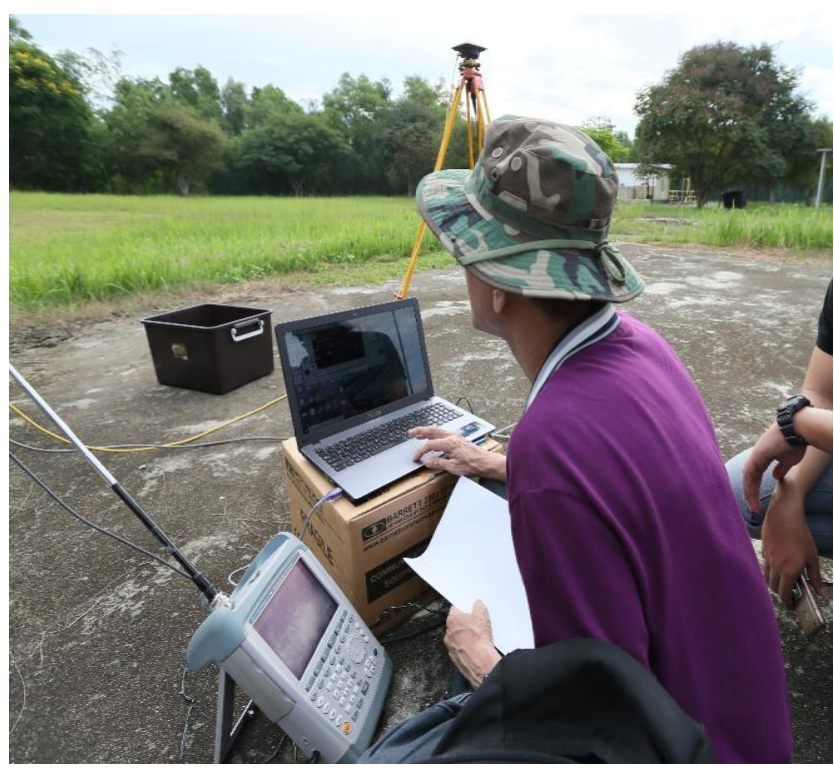

Fig 7. Signal interference investigation by using spectrum analyzer.

\section{RESULTS AND DISCUSSIONS}

\section{A. Multipath Condition}

The colourised polar plots in Figure 8 are produced in 24 hours-time windowing basis. The figure illustrated the azimuth angle $\left(0^{\circ}\right.$ to $\left.360^{\circ}\right)$ corresponds to the satellite azimuth with the surrounding pictures; meanwhile the black dashed circle indicates the satellite elevation $\left(0^{\circ}\right.$ to $\left.90^{\circ}\right)$ at horizontal component. The coloured lines, in addition, show the path of each satellite during the observation period. The multipath magnitude for each satellite path will be given by the aid of scale bar on the right of the figure. From Figure 8, it shows that the south side (red dotted) gave high multipath value because of natural obstructions (trees). These obstruction and high value multipath could be reduced by installing the SISPELSAT GPS antenna at higher level. The multipath processing on MP1 and MP2 are produced in 6 hour-time windowing basis (refer Figure 9 to 16). Table 2 shows the RMS multipath value on each time windows.
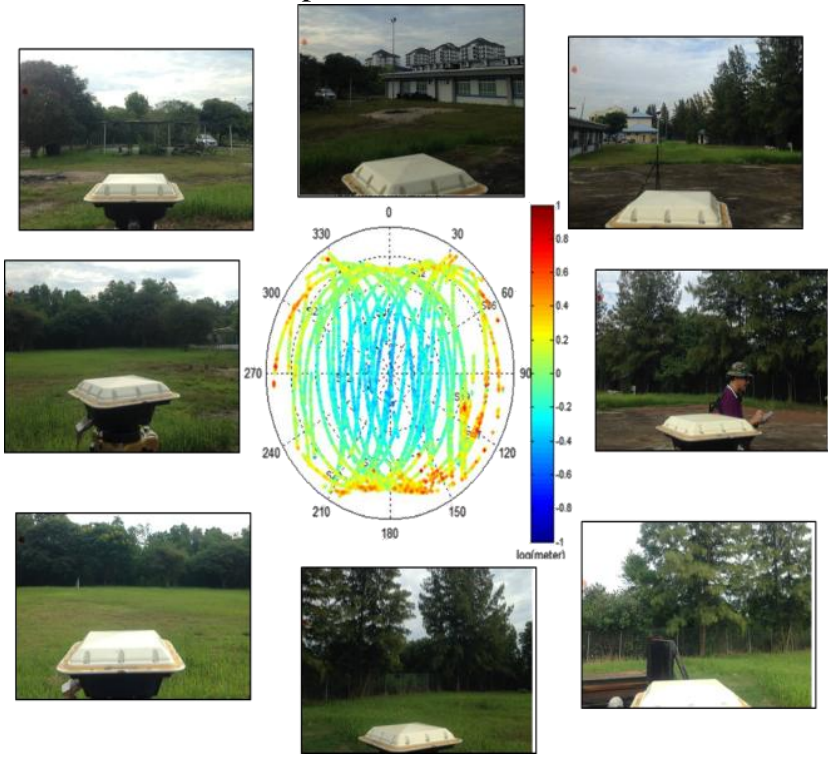

Fig 8. The 24-hour multipath signal scattering at the Port Klang station with an environmental barrier.

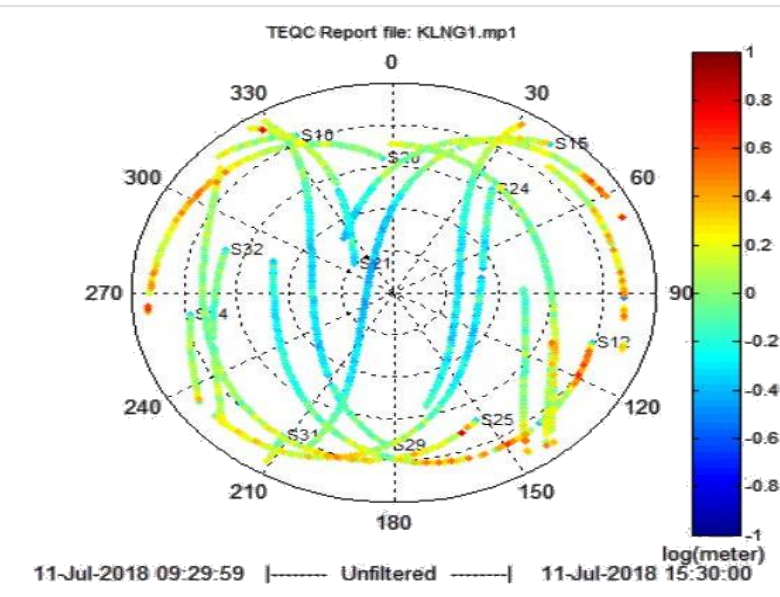

Fig 9. MP1 polar plot at 09:30:00 - 15:30:00 UTC.

Average RMS of MP1: $0.4556 \mathrm{~m}$.

Average no of satellites: 17.

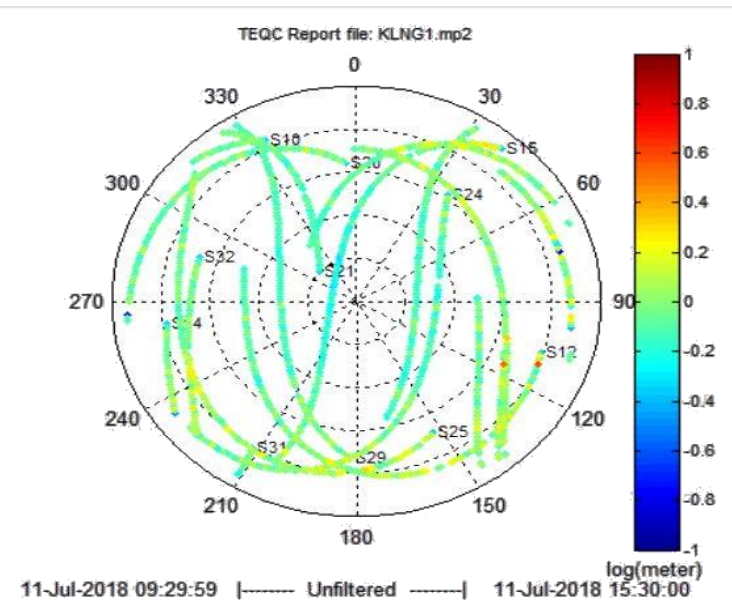

Fig 10. MP2 polar plot at 09:30:00 - 15:30:00 UTC.

Average RMS of MP1: $0.3900 \mathrm{~m}$.

Average no of satellites: 17 .

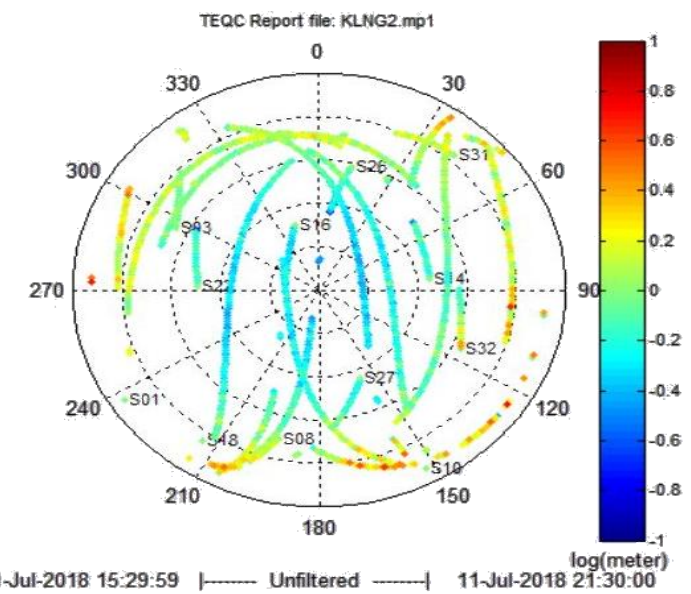

Fig 11. MP1 polar plot at 15:30:00 - 21:30:00 UTC.

Average RMS of MP1: $0.3995 \mathrm{~m}$.

Average no of satellites: 19 .

Published By:

Blue Eyes Intelligence Engineering \& Sciences Publication 


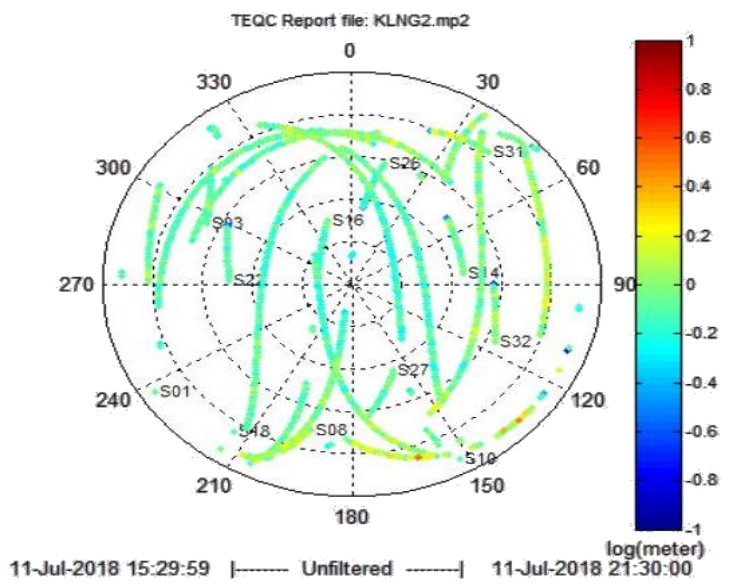

Fige 12. MP2 polar plot at 15:30:00 - 21:30:00 UTC. Average RMS of MP1: $0.3615 \mathrm{~m}$. Average no of satellites: 19 .

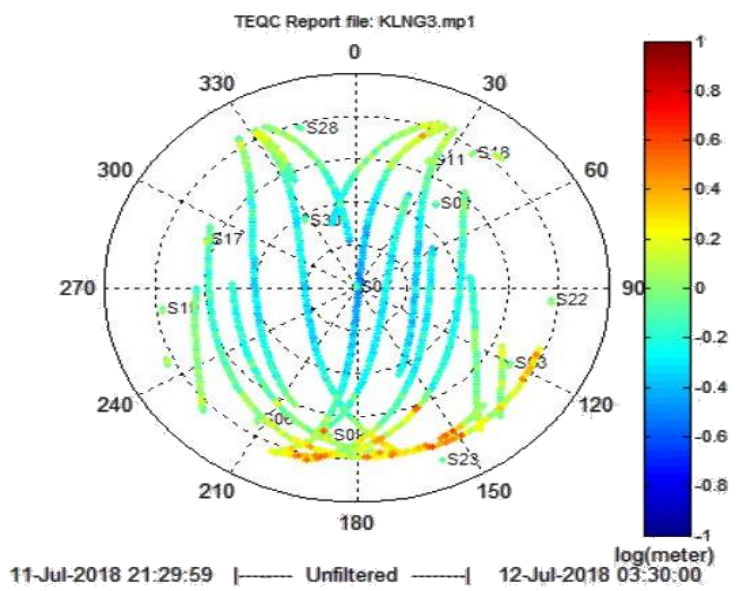

Fig 13. MP1 polar plot at 21:30:00 - 03:30:00 UTC.

Average RMS of MP1: $0.3775 \mathrm{~m}$.

Average no of satellites:20.

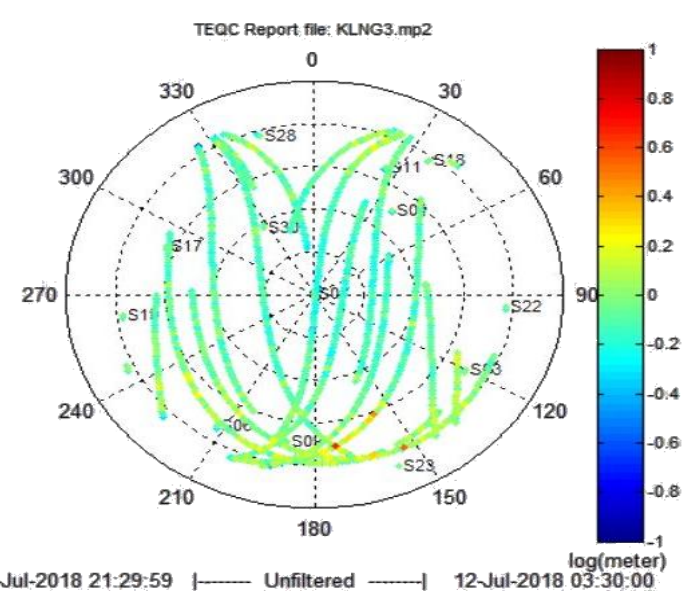

Fig 14. MP2 polar plot at 21:30:00 - 03:30:00 UTC. Average RMS of MP1: $0.3650 \mathrm{~m}$.

Average no of satellites:20.

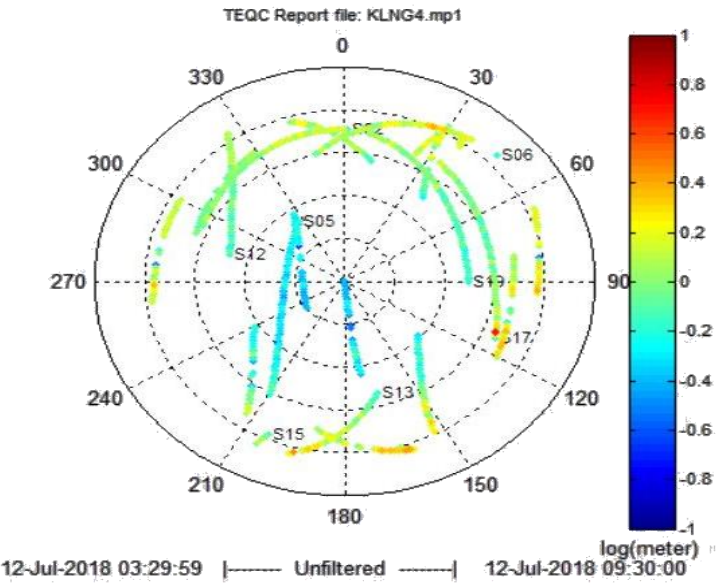

Fig 15. MP1 polar plot at 03:30:00 - 09:30:00 UTC. Average RMS of MP1: $0.4060 \mathrm{~m}$.

Average no of satellites: 17.

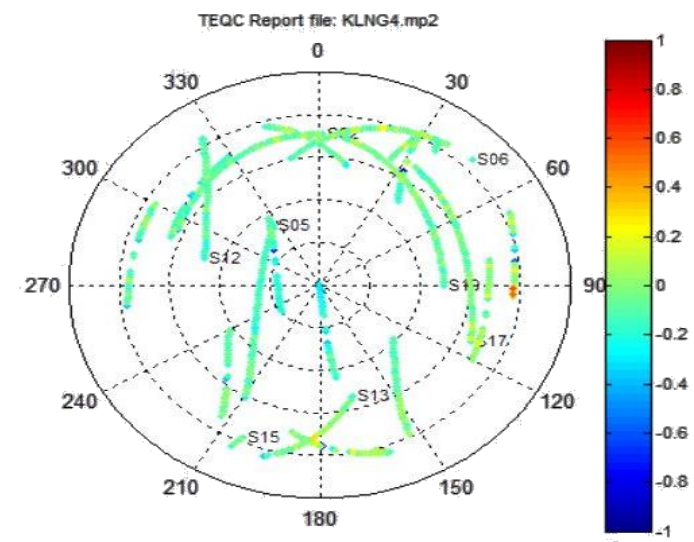

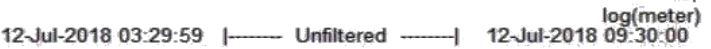

Fig 16: MP2 polar plot at 03:30:00 - 09:30:00 UTC.

Average RMS of MP1: $0.3452 \mathrm{~m}$.

Average no of satellites: 17.

Table 2: Multipath analysis for each L1 \& L2 carrier phase.

\begin{tabular}{|c|c|c|c|c|}
\hline \multicolumn{3}{|c|}{$\begin{array}{l}\text { MP1 and MP2 for all satellites in } \\
\text { view }\end{array}$} & \multicolumn{2}{|c|}{$\begin{array}{l}\text { Satellites with } \\
\text { maximum MP1 and } \\
\text { MP2 }\end{array}$} \\
\hline Time (UTC) & $\mathrm{MP} 1(\mathrm{~m})$ & $\mathrm{MP} 2(\mathrm{~m})$ & $\operatorname{MP} 1(\mathrm{~m})$ & $\mathrm{MP} 2(\mathrm{~m})$ \\
\hline $\begin{array}{l}\text { 09:30:00-15: } \\
\text { 30:00 }\end{array}$ & 0.4556 & 0.3900 & $\begin{array}{l}0.6588 \\
(\mathrm{SV} 06)\end{array}$ & $\begin{array}{l}0.4866 \\
(\mathrm{SV} 17)\end{array}$ \\
\hline $\begin{array}{l}\text { 15:30:00-21: } \\
30: 00\end{array}$ & 0.3995 & 0.3615 & $\begin{array}{l}1.3791 \\
(\mathrm{SV} 01)\end{array}$ & $\begin{array}{l}0.6417 \\
(\mathrm{SV} 29)\end{array}$ \\
\hline $\begin{array}{l}21: 30: 00-03: \\
30: 00\end{array}$ & 0.3775 & 0.3650 & $\begin{array}{l}0.5400 \\
(\mathrm{SV} 22)\end{array}$ & $\begin{array}{l}0.4691 \\
(\mathrm{SV} 32)\end{array}$ \\
\hline $\begin{array}{l}\text { 03:30:00-09: } \\
\text { 30:00 }\end{array}$ & 0.4060 & 0.3452 & $\begin{array}{l}0.6890 \\
(\text { SV09) }\end{array}$ & $\begin{array}{l}0.5622 \\
(\mathrm{SV} 22)\end{array}$ \\
\hline AVERAGE & 0.4097 & 0.3654 & & \\
\hline
\end{tabular}

The average RMS values of MP1 and MP2 for 24 hours observation are $0.4097 \mathrm{~m}$ and $0.3654 \mathrm{~m}$, respectively. From Table 2, it can be noted that the highest multipath occurred during the first 6 hours observation time window [09:30:00 15:30:00] with RMS values of $0.4556 \mathrm{~m}$ and $0.3900 \mathrm{~m}$ for MP1 and MP2, respectively.

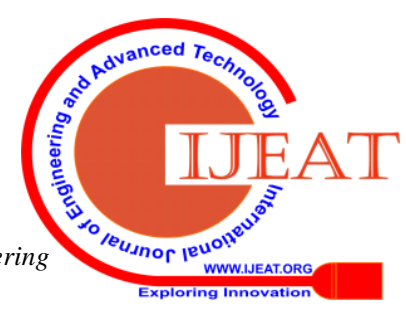


According to Bruyninx et al. (2003), 75\% of the European (EPN) has MP1 value below $0.57 \mathrm{~m}$ and MP2 value below $1.00 \mathrm{~m}$ [9]. Furthermore, $75 \%$ of the international GNSS Services (IGS) stations around the world have an RMS of MP1 and MP2 less than $0.50 \mathrm{~m}$ and $0.75 \mathrm{~m}$, respectively [10]. Hence, the result shows that, the location multipath condition is acceptable to establish the SISPELSAT radio beacon station.

\section{B. SISPELSAT Signal Coverage Simulation}

The result from Figure 2 shows that, Melaka SISPELSAT station can give Port Klang below 10 to $30 \mathrm{~dB}$ of predicted SNR value. Hence, the average predicted value is about 15 to $20 \mathrm{~dB}$ (i.e. $17 \mathrm{~dB}$ ). Figure 17 shows the SNR value recorded at Port Klang from Melaka radio beacon station. The result shows that, the predicted SNR are higher than the recorded value, and there are sudden spikes of data at 4 and 23 UTC hour. Meanwhile, the trend shows energy lost start from 10 UTC, which indicate the night time SNR reading is lower than the day time. Thus, further study on this case is needed. Generally, the Port Klang result received SNR value below $7 \mathrm{~dB}$ at certain time, which unusable and below the ITU recommendation.

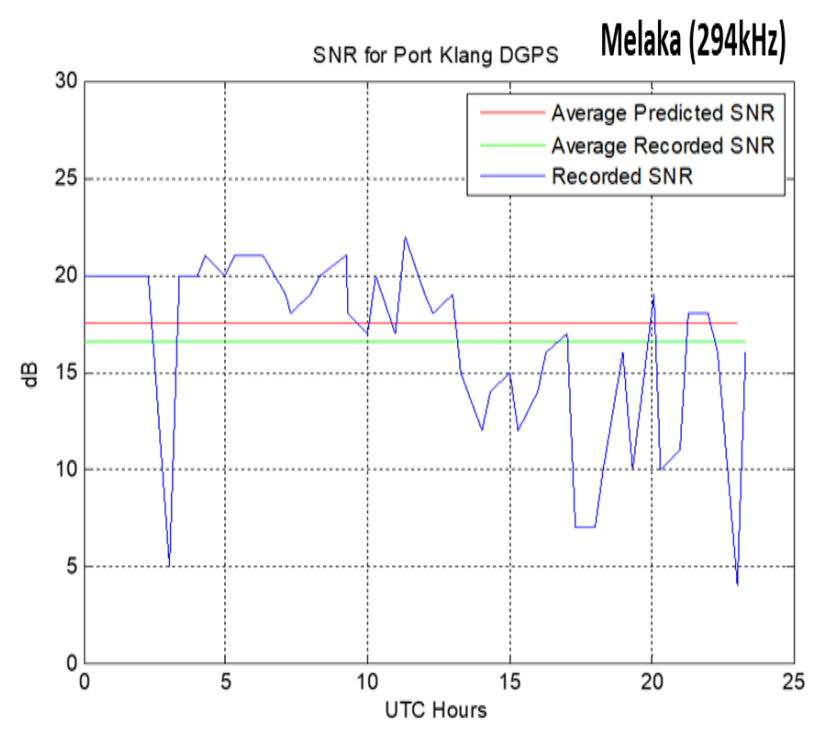

Fig 17. Signal validation on Port Klang.

Figure 18 shows the DGPS signal simulation coverage from Port Klang. The results indicate that, the signal can reach up to North side of Melaka Strait toward Andaman Sea with $12 \mathrm{~dB}$ SNR for maximum and minimum coverage respectively. Nevertheless, the SNR became very low i.e. less than $10 \mathrm{~dB}$ towards the South of the Melaka Straits. The signal only covers part of Melaka waterways for both minimum and maximum coverage. This could be the reason of terrain that blocking the signal from Port Klang toward Melaka.

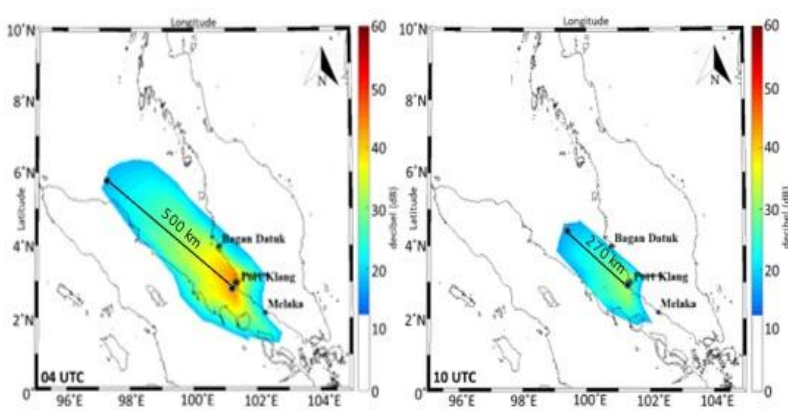

Fig 17. Simulation of minimum and maximum signal coverage for Port Klang.

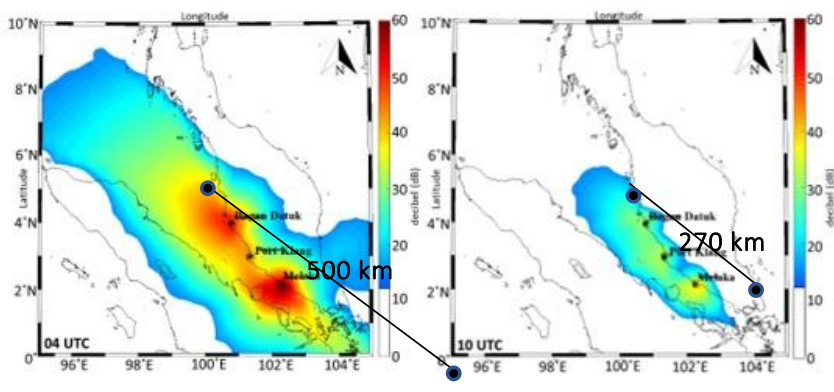

Fig 18. Simulation of maximum and minimum DGPS signal coverage for combination of Bagan Datuk, Melaka SISPELSAT stations and Port Klang.

Furthermore, analysis is conducted which combining all of the existing SISPELSAT with proposed Port Klang station. The signal simulation gives Melaka straits area with more than $45 \mathrm{~dB}$ of SNR for maximum coverage while 20 to $33 \mathrm{~dB}$ at minimum coverage. Therefore, with the addition of Port Klang as SISPELSAT radio beacon could enlarge the coverage and thus give a possibility in providing consistence of signal availability along Melaka Straits.

\section{Signal Interference Investigation}

Figure 19 shows the results of spectrum analyser for GPS and MF signal at Port Klang. The results stated that, the GPS signal frequency with range 1.1 to $1.8 \mathrm{GHz}$ give constant reading values within the noise floor -80 to $-90 \mathrm{dBm}$. Meanwhile, MF signal shows slightly energy increase at 288.095 kHz with $-94.9 \mathrm{dBm}$, but the energy has not significantly affected the signal. Thus, there is no interference with range 1.1 to $1.8 \mathrm{GHz}$ and 250 to $350 \mathrm{kHz}$. It can be indicated at this location there is no signal interfering for GPS data observation and the MSK signal of SIPELSAT.

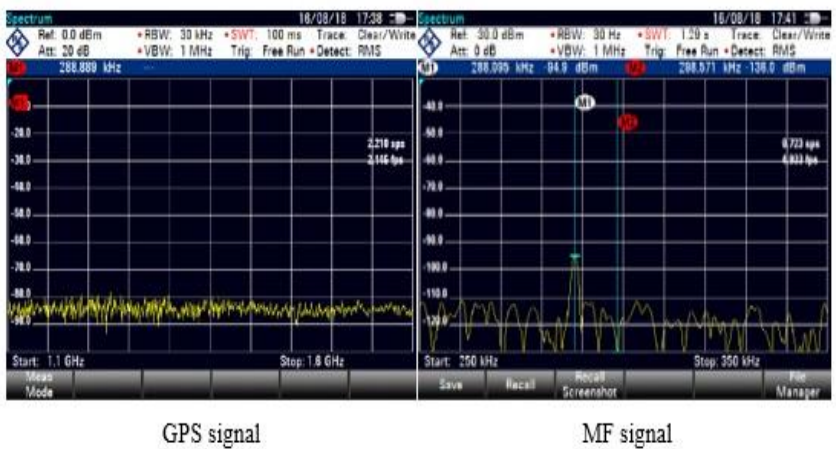

Fig 19. Signal Interference study at MATRAIN Port Klang station for GPS and MF signal.

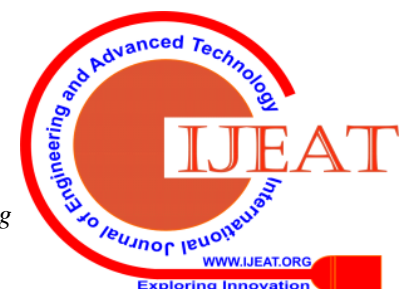




\section{CONCLUSION}

The proposed location of the new SISPELSAT at Port Klang gives an acceptable multipath value which is $0.4097 \mathrm{~m}$ and $0.3654 \mathrm{~m}$ for MP1 and MP2, respectively. This multipath result is in acceptable range for establishing the radio beacon station. The result from DGPS observation also identifies the average value of SNR data from Melaka radio beacon transmitters not reaching the average SNR's predicted value and could be lower than $7 \mathrm{~dB}$, which is below the ITU recommendation. The SISPELSAT signal coverage simulation also give optimum coverage from Port Klang, which cover major part of Melaka Straits. In addition, the combination of Port Klang with Melaka and Bagan Datuk SISPELSAT radio beacon could provide optimum DGPS signal coverage for Melaka Straits. Meanwhile, interference test results also show no interferences on GPS and MF radio signals at this location. Hence, this study found that establishing new SISPELSAT radio broadcasting station at MATRAIN, Port Klang is considered suitable and appropriate for broader radio signal coverage on its harbour and Melaka Straits.

\section{ACKNOWLEDGEMENTS}

The authors would like to acknowledge the Research University Grant (RUG) vot number Q.J1300000.2627.15J02 and R.J130000.7827.4F189 and Marine Department of Malaysia for their contribution to this project by providing funding, sharing expertise, equipment and data. Special thanks to all Geomatic Innovation Research Group $(\mathrm{GnG})$ members for their contribution in this study.

\section{REFERENCES}

[1] IALA, 2015. IALA Recommendation R-121 on the Performance and Monitoring of DGNSS Services in the Frequency Band $283.5-325 \mathrm{kHz}$. International Association of Marine Aids to Navigation and Lighthouse Authorities IALA-AISM, France.

[2] Karsky, D., 2004. Comparing four methods of correcting GPS data: DGPS, WAAS, L-band, and postprocessing. United States Department of Agriculture, Forest Service, Technology \& Development Program.

[3] Ooi W. H, Moslin S.I., Ahmad N., Subari M.D., Musa T.A., Othman R., Omar A.H., Musliman I.A. 2013, May. Integrity Monitoring System for Space-Based Navigation and Positioning in Malaysia. Geospatial World Forum 13-16 May 2013, Beurs-World Trade Centre Rotterdam.

[4] Subari, M.D. and Che Awang, S., 2004, September. Study on global navigation satellite system (GNSS) ground infrastructures in Malaysia. In International Symposium and Exhibition on Geoinformation (Vol. 2004, pp. 21-23th).

[5] Yusup, A., Othman, R., Musliman, I.A. and Han, W.O., 2014 ISKANDARnet CORS Network Integrity Monitoring. Jurnal Teknologi, 71(4).

[6] Razak, M.S.A., TA, M., Othman, R., Yazair, M.F., Sha'ameri, A.Z., Amirudin, A. and Yusof, R.M., 2018. Performance Analysis of Sispelsat Msk-Dgnss Radio Signal in Peninsular Malaysia. International Archives of the Photogrammetry, Remote Sensing and Spatial Information Sciences, 42(4/W9).

[7] International Telecommunication Union (ITU), 2006. Technical Characteristics of Differential Transmissions for Global Navigation Satellite Systems from Maritime Radio Beacons in the Frequency Band $283.5-315 \mathrm{kHz}$ in Region 1 and $285-325 \mathrm{kHz}$ in Regions 2 and 3. ITU-R M.823-3.

[8] Wolfe, D.B., Judy, C.L., Haukkala, E.J. and Godfrey, D.J., 2000 Engineering the world's largest DGPS network. In OCEANS 2000 MTS/IEEE Conference and Exhibition. Conference Proceedings (Cat No. 00CH37158) (Vol. 1, pp. 79-87). IEEE.
[9] Bruyninx, C., Carpentier, G. and Roosbeek, F., 2003, June. Today's EPN and its network coordination. In Proc. of the EUREF symposium held in Toledo, Spain.

[10] Hilla, S. and Cline, M., 2004. Evaluating pseudorange multipath effects at stations in the National CORS Network. GPS Solutions, 7(4), pp. 253-267.

[11] International Telecommunication Union (ITU), 2010. Report ITU-R M.2203(11/2010). Compatibility of amateur service stations with existing services in the range $415-526.5 \mathrm{kHz}$. International Telecommunication Union.

[12] Florence, O., 2014. Radio propagation in outdoor suburban environment: Effect on GSM signal strength. International Journal of Engineering and Science, 3(2014), pp.73-79.

\section{AUTHORS PROFILE}

I am Muhammad Farid Mohd Yazai, affiliated with Geomatic Innovation Research Group (GnG), Faculty of Built Environment and Survey, Universiti Teknologi Malaysia, 81310 Johor Bahru, Johor, Malaysia. For more fetails contact us faridyazair@gmail.com

My name is Tajul Ariffin Musa, currently working with Geomatic Innovation Research Group (GnG), Faculty of Built Environment and Survey, Universiti Teknologi Malaysia, 81310 Johor Bahru, Johor, Malaysia

I am Rusli Othman, currently working with Geomatic Innovation Research Group (GnG), Faculty of Built Environment and Survey, Universiti Teknologi Malaysia, 81310 Johor Bahru, Johor, Malaysia.

Ahmad Zuri Sha'ameri, Geomatic Innovation Research Group (GnG), Faculty of Built Environment and Survey, Universiti Teknologi Malaysia, 81310 Johor Bahru, Johor, Malaysia

Wan Anom Wan Aris, Geomatic Innovation Research Group (GnG), Faculty of Built Environment and Survey, Universiti Teknologi Malaysia, 81310 Johor Bahru, Johor, Malaysia

Ivin Amri Musliman, Geomatic Innovation Research Group (GnG), Faculty of Built Environment and Survey, Universiti Teknologi Malaysia, 81310 Johor Bahru, Johor, Malaysia

Muhammad Syazwan Ab Razak, Geomatic Innovation Research Group (GnG), Faculty of Built Environment and Survey, Universiti Teknologi Malaysia, 81310 Johor Bahru, Johor, Malaysia

Roslee Mat Yusof, Marine Department Malaysia, Ibu Pejabat Laut, Peti Surat 12, Jalan Limbungan, 42007 Pelabuhan Klang, Selangor, Malaysia

Alimuddin Amirudin, Marine Department Malaysia, Ibu Pejabat Laut, Peti Surat 12, Jalan Limbungan, 42007 Pelabuhan Klang, Selangor, Malaysia 